\title{
Las políticas redistributivas de la España no democrática: del objetivo industrializador al sostenimiento de los ingresos de los agricultores (1950-1975)
}

\author{
Redistributive policies in non-democratic Spain: \\ EVA FERNÁNDEZ GARCÍA \\ Universidad Pablo de Olavide, Sevilla
} From protecting industry to assisting farmers (1950-1975)

\begin{abstract}
RESUMEN
Como sugiere el developmental pattern, España desarrolló políticas de apoyo a los agricultores desde la década de 1960, cuando el país experimentó un proceso de rápido crecimiento económico. El volumen de subsidios aumentó y

las políticas de sostenimiento de precios se extendieron a multitud de productos, como había sucedido en los países avanzados democráticos desde 1950. La restricción presupuestaria del régimen no impidió abordar esta redistribución de rentas de los consumidores a los agricultores, puesto que la política se basó fundamentalmente en la regulación del mercado, un aspecto común en los países avanzados, donde apenas entre un $10 \mathrm{y}$ un 20 por 100 del apoyo neto a la agricultura proviene en la actualidad de transferencias en

dinero. Según el Coeficiente de Protección Nominal (CPN) y el Producer Support Estimate (PSE), la protección alcanzó en España niveles similares a los de la CEE desde los años sesenta.

Este resultado contradice tanto la visión de Lindert de que los agricultores obtienen mayor apoyo público en los países democráticos, como la idea olsoniana de que la protección se debe a la presión ejercida por los lobbies de agricultores.
\end{abstract}

PALABRAS CLAVE: Políticas agrarias, Redistribución de la renta, Sostenimiento de precios, Regulación del mercado, Franquismo Códigos JEL: N84, Q18

\section{ABSTRACT}

As suggested by the developmental pattern, policies to support farmers' income developed in Spain from the 1960s onwards, when the country saw a process of rapid economic growth. Direct subsidies promptly increased and price-support policies, similar to those applied for more advanced countries from 1950, expanded for many commodities. Budgetary restrictions were not an obstacle to the redistribution of resources to agriculture, because farm support in Spain was based essentially on market intervention and pricesupport policies. In fact, only 10-20 per cent of today's net transfers to agriculture in advanced countries come from subsidies and monetary transfers. From the 1960s, the intensity of support to Spanish farmers, as measured by the Nominal Protection Coefficient (NPC) and the Producer Support Estimate (PSE), was similar to that in the EEC. This result contradicts both Lindert's assumption that agriculture gets more protection under democratic regimes and the olsonian view that large-scale intervention in agricultural markets results from the collective action of lobby groups.

KEY WORDS: Agricultural Policies, Income Redistribution, Price Support, Market Regulation, Franco's Spain

JEL Codes: N84, Q18 


\section{Introducción ${ }^{1}$}

$\mathrm{M}$

ientras que las políticas agrarias de los países en vías de desarrollo se centran en mantener bajos los precios con el objetivo de proporcionar alimentos baratos a la población urbana y fomentar la industrialización ${ }^{2}$, en los países avanzados se redistribuye renta de los consumidores a los agricultores con políticas que tienen costes presupuestarios altos y que suponen pérdidas significativas de bienestar económico ${ }^{3}$. El apoyo al sector se inició en Europa continental con el proteccionismo arancelario de finales del siglo XIX. Las políticas de sostenimiento de las rentas agrarias comenzaron a desarrollarse en los países avanzados en el período de entreguerras y los niveles de protección aumentaron sustancialmente durante la Gran Depresión y desde $1950^{4}$. Los aranceles dejaron de constituir la principal fuente de protección de los agricultores y, desde 1929, gran parte del apoyo se consiguió a través de la regulación del mercado, la garantía de precios mínimos y la retirada de excedentes agrarios, medidas que se complementaron con políticas de restricción de la oferta, protección comercial no arancelaria, financiación de exportaciones y subsidios ${ }^{5}$. Como sugiere el developmental pattern (Lindert, 1991) o developmental paradox (Anderson, 1995), la protección a los agricultores aumenta con el crecimiento económico y se relaciona inversamente con el peso de la agricultura en el PIB y en el empleo ${ }^{6}$. La disminución del tamaño del sector reduce el coste político de apoyar a los agricultores y elimina la oposición de los contribuyentes y consumidores a transferir rentas

[Fecha de recepción del original, enero de 2008. Versión definitiva, abril de 2008]

1 Esta investigación ha recibido apoyo financiero del Ministerio de Educación (SEJ2006-08188/ECON). Agradezco los comentarios de James Simpson, de los participantes en el Spring Meeting of Young Economists 2007 e Iberometrics III y de los cuatro evaluadores anónimos de Investigaciones de Historia Económica. Los posibles errores corresponden a la autora.

2 Con este objetivo, imponen altos impuestos al sector agrario o perjudican indirectamente a los agricultores con la política macroeconómica (tasa de cambio sobrevaluada, protección del sector industrial e impuestos a las exportaciones agrarias y a las importaciones de inputs). Generalmente, los recursos que los países pobres transfieren a la agricultura (crédito, infraestructura, extensión) son inferiores a los recursos extraídos. Además, se establecen impuestos más altos a los sectores agrarios con mayor ventaja comparativa y los grandes propietarios se benefician más de las transferencias al sector agrario (Krueger, Schiff y Valdés, 1991). Sobre este tipo de políticas, véanse también Bates (1983); Binswanger y Deininger (1997); Bale y Lutz (1981); Tyers y Anderson (1992), cap. 2; y Stevens y Jabara (1988).

3 Lindert (1991), Anderson y Hayami (1986), y OECD (2002a).

4 Véanse Gardner (1987 y 1992) y Libecap (1998) sobre la importancia de las políticas para combatir la Gran Depresión en la configuración del sistema de protección a los agricultores de Estados Unidos desde 1950.

5 Sumner y Tangermann (2002), p. 2004; Tracy (1989), p. 250; Federico (2005), p. 197; Libecap (1998), y Servolin (1989).

$6 \quad$ Lindert (1991); Fulginiti y Shogren (1992); Beghin y Kherallah (1994); Gardner (1987); De Gorter y Tsur (1991); Honma y Hayami (1986), y Thies y Porche (2007). 
al sector ${ }^{7}$. Según Anderson y Hayami (1986, p. 3), cuanto más acelerado es el crecimiento económico, más rápidamente se adoptan políticas de protección. Además, según Lindert (1991), los agricultores consiguen mayor protección si viven en países democráticos.

El developmental pattern se produce, según Olson (1965 y 1985) y Becker (1983), porque la disminución del tamaño del sector agrario facilita la acción colectiva de los agricultores, al reducir los costes de organización y prevenir el free riding. De esta forma, la intervención a gran escala de los mercados agrarios se justifica por la presión ejercida por las organizaciones de agricultores ${ }^{8}$. Los análisis teóricos presuponen, además, una relación positiva entre democracia y apoyo a las rentas agrarias", aunque Federico ha señalado recientemente que "this hypothesis is not entirely supported by some recent econometric work"10. Beghin and Kherallah (1994), por ejemplo, observaron una correlación no lineal entre la asistencia a los agricultores y el sistema político para 25 países en 1982-1987, y Swinnen et al. (2001) y Olper (2001) estimaron, en sus respectivos trabajos, un impacto débil de la democracia en el nivel de protección a los agricultores. De hecho, Corea del Sur y Taiwán, dos de las economías con mayores niveles de protección de sus agricultores en la actualidad, adoptaron políticas de apoyo en los años sesenta y setenta, cuando vivían bajo dictaduras militares ${ }^{11}$.

Con el objetivo de comprobar la influencia de los sistemas políticos en el nivel de apoyo al sector, este artículo analiza la política agraria de España en el período 1950-1975. Como sugiere el developmental pattern, a pesar de que el país vivía bajo un

Swinnen et al. (2001), p. 29; Honma y Hayami (1986). Las políticas de protección se desarrollan en respuesta al farm problem, que se produce como consecuencia de la demanda inelástica de alimentos y el aumento de la productividad total provocados por el desarrollo económico (Schultz, 1945); pero también a la mayor vulnerabilidad de los productores agrarios a las fluctuaciones del mercado, puesto que la producción agraria es inelástica y los precios caen de forma abrupta en los períodos de crisis económica (Hathaway, 1963). Tracy (1989); Andreosso-O'Callaghan (2003), y Federico (2005). Por el contrario, Gardner (1987) encontró una relación no lineal entre el tamaño del grupo y su poder político. En contraste con la teoría de la acción colectiva, De Gorter y Tsur (1991) consideran que los políticos transfieren rentas a ciertos grupos a cambio de apoyo político con el objetivo de maximizar sus posibilidades de ser reelegidos o aumentar su legitimidad en el caso de una dictadura.

9 De Gorter y Tsur (1991).

10 Federico (2005), p. 218. De Gorter y Swinnen (2002, p. 1901) destacaron la escasez de estudios empíricos y teóricos sobre la influencia de las instituciones políticas en las políticas agrarias.

11 Anderson (1986). Entre 1960 y 1980, el PIB per capita de Corea y Taiwán aumentó a una tasa anual del 6,9 y del 6,6 por 100, respectivamente. El crecimiento económico se acompañó de un rápido descenso de la importancia de la agricultura en el PIB y el empleo y de una caída del gasto familiar en alimentos, pero también de un descenso drástico de la ventaja comparativa de la agricultura respecto al sector industrial, lo que supuso un aumento importante de la dependencia de las importaciones de alimentos. Anderson (1986), pp. 9-13. 
régimen político no democrático, el apoyo a los agricultores aumentó desde la década de 1960, cuando España experimentó un proceso de rápido crecimiento económico. Después del período autárquico, las políticas agrarias mostraron la creciente preocupación del régimen por el nivel de ingresos de la población rural. La transferencia de subsidios aumentó y las políticas de sostenimiento de precios y de intervención del mercado se extendieron a multitud de productos, como había sucedido en los países avanzados democráticos durante la Gran Depresión y desde 1950. Más aún, según el Coeficiente de Protección Nominal (CPN) y el Producer Support Estimate (PSE), la protección alcanzó en España niveles similares a los de la Comunidad Económica Europea (CEE). La restricción presupuestaria del régimen franquista no impidió transferir rentas a los agricultores, puesto que las políticas de apoyo al sector se basaron en la regulación del mercado, un aspecto común a los países avanzados en la actualidad, donde apenas entre un 10 y un 20 por 100 de las transferencias netas a la agricultura provienen de subsidios o de transferencias en dinero ${ }^{12}$. Aunque, según el developmental pattern, con el desarrollo económico los países comienzan a transferir rentas al sector, los niveles de protección a los agricultores varían sustancialmente en los países occidentales. Australia, Nueva Zelanda o Canadá apenas han desarrollado políticas agrarias protectoras ${ }^{13}$, mientras que en Estados Unidos el grado de sostenimiento de las rentas agrarias es inferior que en los países europeos avanzados y Japón. Por ese motivo, el segundo objetivo del artículo es explicar por qué en España se alcanzaron desde 1960 niveles de protección comparativamente altos.

El artículo se divide en cuatro partes. Tras esta introducción, en la segunda sección se analizan los cambios introducidos en la política agraria española en 1950-1975 y se constata la adopción de políticas de apoyo a los agricultores desde 1960. En la tercera se compara el nivel de protección obtenido por los agricultores en España y en la CEE en 1960-1980, y se comprueba que alcanzó niveles similares a los de otros países occidentales desde 1960. No obstante, como en otras naciones, la protección no se extendió a todos los productos agrarios, sino que recibieron mayor asistencia los productos con baja elasticidad de oferta o demanda. En la cuarta sección se considera que, según la teoría de Anderson y Hayami (1986), la intensidad de la protección y el apoyo a los agricultores españoles se debió a la escasa ventaja comparativa de España en agricultura. En la quinta, por último, se presentan las conclusiones.

$\operatorname{OECD}(2002 a)$.

13 De Gorter y Tsur (1991). 


\section{La política agraria durante el franquismo: la introducción de objeti- vos redistributivos desde 1960}

La Guerra Civil supuso un aumento sustancial de la intervención en los mercados agrarios con el objetivo de garantizar el suministro de alimentos y materias primas ${ }^{14}$. Los instrumentos y los organismos públicos que se establecieron durante la contienda (como el Servicio Nacional del Trigo) se mantuvieron con el franquismo. Entre 1939 y la década de 1960, el régimen adoptó una política económica que discriminó a la agricultura frente a los objetivos de industrialización y que perjudicó las posibilidades de crecimiento del sector, aunque permitió una importante acumulación de capitales a los grandes propietarios ${ }^{15}$. Durante la década de 1940, la política autárquica e intervencionista del régimen se centró en la sobrevaluación de la peseta, la protección de la industria y la intervención de los mercados. La política agraria trató de conseguir la autosuficiencia alimentaria y de aumentar la producción de los productos tradicionales de exportación (vino, aceite de oliva y naranjas), pero el rígido intervencionismo causó una brusca caída de la producción, de la productividad y del nivel de vida general de la población. Se fijaron precios muy bajos con el objeto de reducir los precios de consumo, lo que desincentivó el cultivo y desvió parte de la producción hacia el mercado negro ${ }^{16}$. Muchos productos no pudieron exportarse como consecuencia del descenso de la oferta (patatas, arroz y aceite de oliva) y la sobrevaluación de la peseta perjudicó la exportación de vino y naranjas. La disminución de la producción agraria obligó a racionar los alimentos y muchos productos tuvieron que importarse ${ }^{17}$. La política agraria benefició a los terratenientes ${ }^{18}$, mientras que el nivel de vida de los pequeños agricultores y de los jornaleros disminuyó sustancialmente. Los grandes propietarios y los empresarios agrícolas que empleaban mano de obra contratada se beneficiaron también de una oferta de trabajo abundante y barata, puesto que el peso del empleo agrario disminuyó sólo un 5 por 100 entre 1944 y 1954, después de un flujo neto de la población activa a la agricultura durante y después de la Guerra Civil (Gráfico 1). Los salarios agrarios favorecieron a grandes propietarios y empresarios agrícolas, especialmente a los productores de trigo, quienes también se beneficiaron de los precios más elevados que conseguían

14 Para el caso del trigo, véase Barciela (1981a).

15 Sobre la política agraria desarrollada durante el primer franquismo y los años sesenta, véanse Barciela (1985), (1986), (1987) y (1997); y Barciela et al. (1996 y 2001).

16 Barciela (1981b), (1994) y (2003a); y Gutiérrez (1983).

17 Barciela et al. (2001), y Narváez (1980). Después de la Guerra Civil, las transferencias desde la agricultura a la industria aumentaron como consecuencia del descenso de los salarios agrarios, la caída de los términos de intercambio internos y la sobrevaluación de la peseta. Naredo (1986), pp. 461-465. 


\section{GRÁFICO 1}

PESO DE LA AGRICULTURA EN LA POBLACIÓN ACTIVA Y EN EL PIB, 1920-2000

(porcentajes)

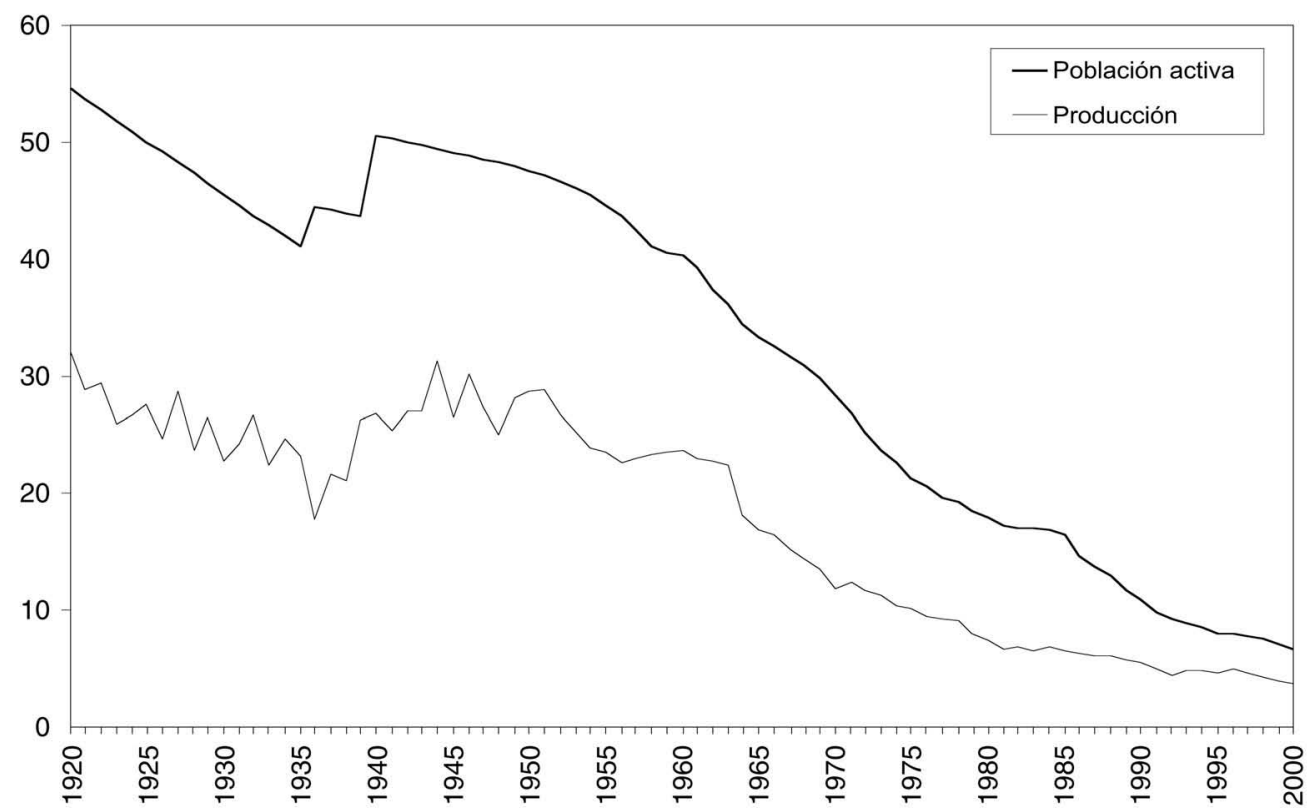

Fuentes: Prados (2003).

en el mercado negro. En los primeros veinte años, gran parte de la inversión pública en el sector se concentró en un plan poco exitoso de extensión del regadío, que antes de 1960 obtuvo resultados limitados en relación a los recursos invertidos ${ }^{19}$.

El régimen franquista abandonó lentamente sus principios intervencionistas y autárquicos durante los años cincuenta e introdujo cambios en la política de precios de los productos agrarios desde 1952 — con el nuevo ministro de Agricultura, Rafael Cavestany-, si bien el monopolio del Servicio Nacional del Trigo y los precios fijos para este producto continuaron ${ }^{20}$. La tasa del trigo se elevó un 47 por 100 entre 1951 y 1956, lo que

\footnotetext{
19 Sociedad de Estudios y Publicaciones (1969), p. 25; Barciela (1986); y Barciela et al. (2001), pp. 101-105 y 210215. Véase también Bosque (1984).

20 A partir del Servicio Nacional del Trigo, en 1968 se creó el Servicio Nacional de Cereales, cuyas funciones asumió el Servicio Nacional de Productos Agrarios (SENPA) en 1971. El monopolio estatal triguero desapareció en 1984. Véase, por ejemplo, Barciela (2007).
} 
CUADRO 1

CONSUMO DE ALIMENTOS EN ESPAÑA, 1950-1980

(kilogramos anuales por habitante)

\begin{tabular}{rccccccc}
\hline Año & Cereales & Azúcar & Vegetales & Fruta & Carne & Huevos & Leche \\
\hline $\mathbf{1 9 5 5}$ & 106 & 13 & 8 & 67 & 14 & 5 & 58 \\
$\mathbf{1 9 6 0}$ & 108 & & & & 19 & 5 & 60 \\
$\mathbf{1 9 6 5}$ & 92 & 22 & 10 & 89 & 28 & 10 & 59 \\
$\mathbf{1 9 7 0}$ & 76 & 27 & 7 & 79 & 45 & 12 & 81 \\
$\mathbf{1 9 7 5}$ & 80 & 27 & 7 & 132 & 61 & 16 & 95 \\
$\mathbf{1 9 8 0}$ & 76 & 28 & 6 & 144 & 69 & 17 & 104 \\
\hline
\end{tabular}

Fuentes: Barciela et al. (2005)

incentivó el aumento de la producción y aseguró el abastecimiento ${ }^{21}$. También se fijaron precios mínimos para algunos productos (vino, aceite de oliva) desde principios de los cincuenta. No obstante, la política agraria de Franco continuó sin preocuparse por los ingresos de los agricultores durante esta década, hecho que coincide con la teoría del developmental pattern. Casi dos decenios después de la Guerra Civil, España era un país pobre. En 1955, el PIB per capita apenas suponía dos tercios del de los países europeos avanzados y un 35 por 100 del de Estados Unidos. Una parte sustancial de la población activa, casi un 50 por 100, continuaba, además, empleada en la agricultura.

El proceso de rápida industrialización y crecimiento económico se inició en España a partir de 1960. Entre 1958 y 1975, el PIB per capita aumentó a una tasa anual del 6 por $100^{22}$. Casi dos millones de agricultores españoles emigraron del campo a la ciudad ${ }^{23}$, y el porcentaje de agricultores en la población activa se redujo sustancialmente en apenas quince años. En 1975 el empleo en el sector representaba sólo el 20 por 100 de la población activa total (Gráfico 1). La caída de la población agraria continuó desde entonces, pero se necesitaron otros veinticinco años para reducir este porcentaje hasta el 5 por 100. El peso de los alimentos en el gasto total también disminuyó rápidamente: aunque suponía aún un porcentaje significativo del presupuesto familiar en 1973-1974 (38 por 100), su importancia 


\section{GRÁFICO 2}

ÍNDICE DE PRECIOS REALES RECIBIDOS POR LOS AGRICULTORES, 1935-2000 (1995=100)

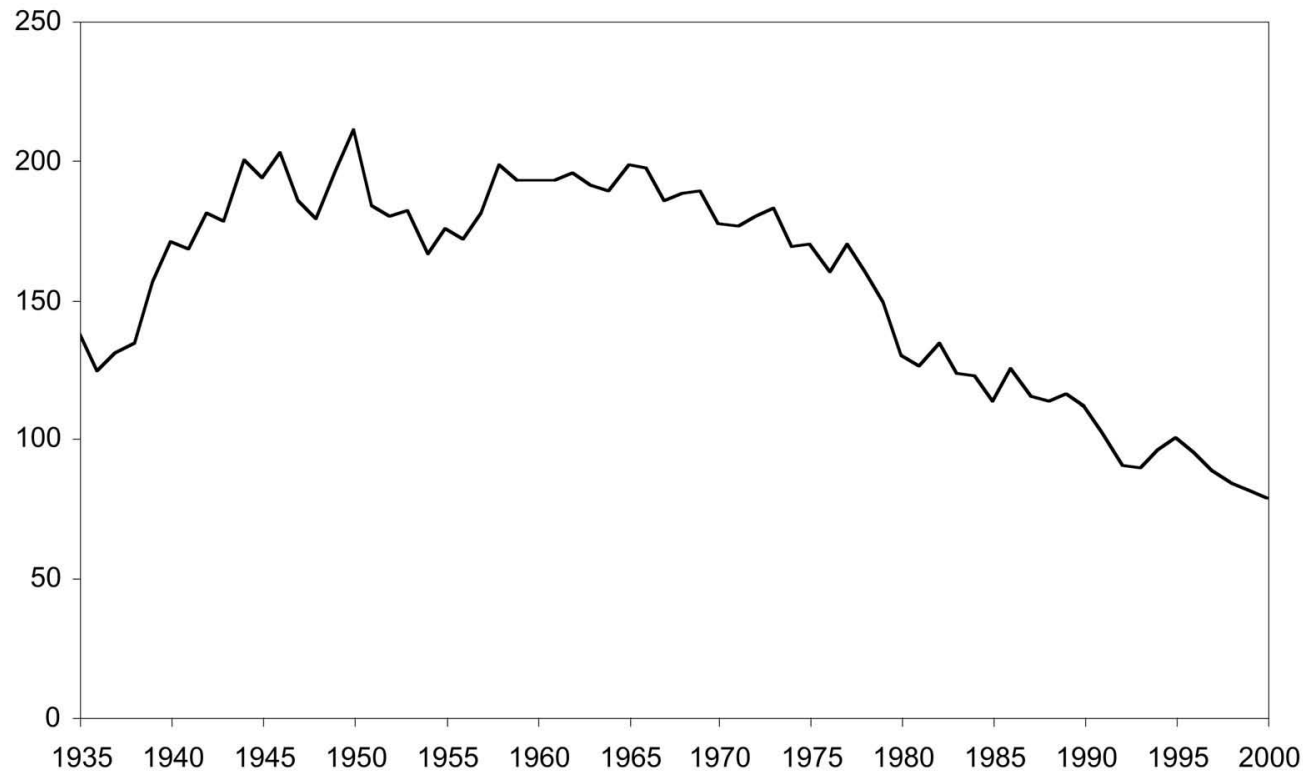

Fuentes: Prados (2003), tabla A.11.10.

había descendido rápidamente desde finales de los años cincuenta (53 por 100 en 1958) ${ }^{24}$. Además, como consecuencia del aumento de los ingresos por habitante, la distribución del gasto en alimentación cambió. El consumo de cereales se redujo un 25 por 100 entre 1955 y 1975 (Cuadro 1); la demanda de huevos, por el contrario, se multiplicó por tres, la de leche por dos y el consumo de azúcar se incrementó de 12 a 30 kilos anuales por persona. El aumento más importante se produjo en el caso de la carne, cuya demanda se multiplicó por cuatro en veinte años hasta 60 kilos anuales en 1975, una cantidad, no obstante, baja en comparación con el promedio de los países de la OCDE ${ }^{25}$.

24 INE (varios años). El descenso de la demanda interna de alimentos se puede compensar con la expansión de las exportaciones, como ocurrió en España. El valor de las exportaciones agrarias en pesetas constantes de 1995 se incrementó a una tasa anual del 4,4 por 100 entre 1964 y 1973, y su importancia en los ingresos del sector pasó del 16 al 30 por 100 en el mismo período. Casi el 50 por 100 de las exportaciones consistieron en vino, frutas y aceite, calculado a partir de Anuario de Producciones Agrarias y Estadísticas de Comercio Exterior.

25 OECD (1974), p. 10. 


\section{CUADRO 2}

SUBSIDIOS E INVERSIÓN PÚBLICA EN LA AGRICULTURA ESPAÑOLA, 1957-1989

(pesetas constantes de 1995)

\begin{tabular}{|c|c|c|c|c|c|c|}
\hline & \multirow{2}{*}{$\begin{array}{l}\text { Subsidios } \\
\text { (millones } \\
\text { de pesetas) }\end{array}$} & \multirow{2}{*}{$\begin{array}{l}\text { Inversión } \\
\text { pública } \\
\text { (millones } \\
\text { de pesetas) }\end{array}$} & \multicolumn{2}{|c|}{$\begin{array}{l}\text { Porcentaje del valor } \\
\text { de la producción }\end{array}$} & \multirow{2}{*}{$\begin{array}{l}\text { Subsidios } \\
\text { por } \\
\text { agricultor } \\
\text { (pesetas) }\end{array}$} & \multirow{2}{*}{$\begin{array}{l}\text { Transferencias totales } \\
\text { como porcentaje del } \\
\text { gasto público total }\end{array}$} \\
\hline & & & Subsidios & $\begin{array}{l}\text { Inversión } \\
\text { pública }\end{array}$ & & \\
\hline 1957 & 1.338 & & 0,1 & & & 0,1 \\
\hline 1960 & 28.491 & 112.579 & 1,3 & 5,3 & 6.066 & 8,9 \\
\hline 1965 & 51.729 & 197,461 & 2,0 & 7,7 & 11.915 & 10,7 \\
\hline 1970 & 68.678 & 168.347 & 2,6 & 6,3 & 18.002 & 5,3 \\
\hline 1975 & 93.866 & 207.326 & 4,3 & 9,5 & 30.851 & 4,9 \\
\hline 1980 & 110.038 & 188.453 & 5,1 & 8,7 & 51.929 & 3,1 \\
\hline 1985 & 135.048 & 153.173 & 7,0 & 7,9 & & \\
\hline 1989 & 118.754 & 143.611 & 5,7 & 6,9 & & \\
\hline
\end{tabular}

Fuentes: Anuario de Producciones Agrarias (varios años) y Carreras et al. (2005).

Los ingresos relativos de los agricultores descendieron desde la década de 1960. Los términos de intercambio internos de la agricultura, que habían comenzado a disminuir en 1954, llegaron a alcanzar un índice de 49 en 1975. Los precios reales percibidos por los agricultores en 1965-1975 cayeron un 50 por 100 (Gráfico 2). El rápido crecimiento económico, la reducción del tamaño del sector agrario y los cambios en la demanda favorecieron el desarrollo de una política de protección y sostenimiento de rentas. Los impuestos municipales y provinciales que gravaban los productos agrarios se redujeron sustancialmente ${ }^{26}$. La devaluación de la peseta en 1959 eliminó el gravamen indirecto sobre la exportación, medida que impulsó las ventas exteriores de productos hortofrutícolas y de vino ${ }^{27}$. Desde 1957 se comenzaron a conceder subsidios a los agricultores, cuyo valor en términos reales se multiplicó por 50 hasta representar un 2 por 100 del valor de la producción agraria en 1965 (Cuadro 2). Los primeros subsidios sólo pretendían incentivar la introducción de mejoras o la reconversión de las explotaciones en cultivos más rentables (pastos, cereales pienso), pero no apoyar o sostener las rentas de los agricultores. No obstante, desde 1963, los productores de trigo comenzaron a recibir subsidios destinados a elevar sus ingresos.

26 Gómez Orbaneja y Checchi (1980).

27 Reig y Picazo (2002), p. 27. Sobre la política agraria en los años sesenta, véase también Cercós (1983). 
Las transferencias se asignaron a las explotaciones de menos de 14 hectáreas o con rendimientos bajos y se establecieron ayudas para estimular la formación de asociaciones de productores trigueros. Entre 1963 y 1966, las ayudas al trigo aumentaron sustancialmente, por lo que su peso en las transferencias agrarias totales se incrementó en apenas tres años del 24 al 60 por 100 del total. Los precios de tasa para este producto también se fijaron en niveles excepcionalmente altos, con lo que a principios de los años sesenta se dio al trigo un papel central en la política agraria, como en el periodo autárquico. El régimen lo consideraba un producto de primera necesidad, por lo que los subsidios y las tasas intentaban evitar la reducción de la oferta de trigo frente a la de los cereales pienso, con el objetivo de garantizar el suministro ${ }^{28}$. La excesiva protección a los productores trigueros desincentivó la producción de cereales pienso, como señaló la FAO en su informe de 1966; hecho que constituyó un importante obstáculo a la expansión ganadera en un momento de aumento de la demanda de bienes de mayor elasticidad-renta (carne, leche) por el crecimiento del PIB per capita y el aumento de la población urbana. Como consecuencia, la escasez relativa de productos ganaderos y la necesidad de importaciones provocó un ascenso de los precios y agravó el déficit de la balanza comercial ${ }^{29}$.

Los cambios en la política agraria se aceleraron desde mediados de los años sesenta, después de la publicación del informe de la FAO. Muchas de sus conclusiones, especialmente las relacionadas con la política triguera, se incluyeron en el II Plan de Desarrollo (1968-1972), en el que se comenzó a mostrar una preocupación gubernamental por el nivel de ingresos de los agricultores. El Plan destacó el interés de la Administración por elevar el bienestar de la población rural y asegurar mayor paridad entre los ingresos agrarios y no agrarios ${ }^{30}$. A través de la política de precios, el II Plan pretendía impedir la caída de los ingresos relativos de los agricultores, así como orientar la producción y corregir los desequilibrios entre la oferta y la demanda. El objetivo se centró no sólo en estabilizar los precios de los agricultores, sino también en aumentar la educación de la población rural para mejorar la productividad del trabajo en el campo ${ }^{31}$. No obstante, el presupuesto proyectado para agricultura, que ascendió a 90.000 millones de pesetas, se centró en la expansión del regadío y la promoción de la reforma estructural, la industrialización, y el desarrollo

Cuando los países se industrializan se convierten en importadores netos de productos agrarios, al disminuir su ventaja comparativa en agricultura. Por este motivo, los gobiernos de los países avanzados apelaron a la seguridad alimentaria para intervenir en los mercados agrarios y apoyar a los agricultores. Anderson y Hayami (1986), p. 3; De Gorter y Swinnen (2002), pp. 1899-1900; y Anderson (1995).

FAO (1966). Véanse también Barciela et al. (2001) y Clar (2005).

Narváez (1980), pp. 100-101 y 136; y Barciela et al. (1996), p. 93.

Comisaría del Plan de Desarrollo Económico y Social (1972), y MAPA (1971). Véanse también Tamames (1970), pp. 270-274, y Narváez (1980), p. 101. 
rural y la mejora de la comercialización, pero sólo un 7 por 100 correspondió a subsidios. A finales de 1970, cuando se había ejecutado el 60 por 100 de los gastos planeados, la mitad de las inversiones se había destinado a la expansión de la superficie de regadío, mientras que el gasto en agricultura, principalmente reservado a repoblación forestal y concentración parcelaria, sólo había supuesto un tercio del total y el gasto en I+D, educación y formación profesional apenas había alcanzado un 2 por $100^{32}$.

No obstante, de acuerdo con las directrices del Plan, el gobierno dobló los subsidios a los agricultores hasta alcanzar 95.000 millones de pesetas (de 1995), lo que supuso un 4 por 100 del valor de la producción agraria en 1975 (Cuadro 2). Como consecuencia, los subsidios por agricultor se multiplicaron por cinco desde 1960 hasta alcanzar 30.000 pesetas en 1975. Por el contrario, la inversión pública se incrementó sólo un 10 por 100 desde mediados de los sesenta, puesto que los esfuerzos inversores se habían concentrado a principios de la década, si bien, en 1975, aquélla significaba casi un 10 por 100 del valor de la producción. Desde finales de los años sesenta, dos tercios de las transferencias a los agricultores se destinaron a la financiación del uso de inputs, especialmente combustible, y, en menor medida, semillas y fertilizantes (Cuadro 3). Los pagos basados en la producción, sin embargo, significaron sólo entre un 20 y un 30 por 100 de las transferencias, y la mayoría se destinó a financiar el almacenamiento público o privado de parte de la producción y a la garantía de precios desde 1970. A pesar del aumento de las ayudas al sector, el coste de las transferencias disminuyó, debido a la caída del peso de la agricultura en la economía. Todas las transferencias (subsidios e inversión pública) suponían en 1965 un 11 por 100 del total del gasto público, pero el porcentaje diminuyó al 5 por 100 diez años después, a pesar del incremento de las transferencias per capita. Con el comienzo de la transición política, los esfuerzos para aumentar los subsidios a los agricultores continuaron, hasta alcanzar 40.000 millones de pesetas, un 7 por 100 del valor de la producción. Sin embargo, los subsidios por agricultor se incrementaron sólo un 35 por 100 en los primeros años de la democracia y la inversión pública en el sector se redujo a menos de 7 por 100 en 1989. Además, la importancia de las transferencias a los agricultores en el gasto total cayó al 3 por 100 en 1980 (Cuadro 2) ${ }^{33}$.

Los cambios en la política agraria introducidos por el II Plan de Desarrollo se reforzaron con la creación, en 1968, del Fondo de Ordenación y Regulación de Producciones y Precios Agrarios (FORPPA, en adelante), un nuevo organismo público cuyas funciones y objetivos se basaron en la agencia francesa Fonds d'Orientation et

32 Comisaría del Plan de Desarrollo Económico y Social (1972).

33 La política agraria, incluido el sistema de apoyo a los precios, no cambió sustancialmente desde 1975. Sobre la política agraria de la transición y los años ochenta, véanse Barciela et al. (1996), p. 95-96, y Barceló (1983). 


\section{CUADRO 3}

SUBSIDIOS TRASFERIDOS A LOS AGRICULTORES SEGÚN SU PROPÓSITO, 1967-1975

(millones de pesetas corrientes)

\begin{tabular}{lccc}
\hline & 1967-1969 & $\mathbf{1 9 7 0 - 1 9 7 2}$ & $\mathbf{1 9 7 3 - 1 9 7 5}$ \\
\hline Pagos basados en la producción & 21 & 33 & 22 \\
Sostenimiento de precios & 25 & 65 & 75 \\
Almacenamiento privado o público & 75 & 18 & 12 \\
Pagos basados en el uso de inputs & 70 & 58 & 62 \\
Gasolina & 75 & 73 & 81 \\
Semillas y abonos & 12 & 15 & 10 \\
Tratamientos contra las plagas & 8 & 8 & 3 \\
Plan de mejora del ganado & 6 & 4 & 5 \\
Otros & 9 & 8 & 15 \\
\hline
\end{tabular}

Fuentes: MAPA-UAM (1977).

de Régularisation des Marchés Agricoles (FORMA) ${ }^{34}$. En el FORPPA se centralizó y coordinó la intervención del mercado de todos los productos agrarios, hasta ese momento dirigida por las antiguas instituciones creadas en la Guerra Civil o a principios de los años cincuenta ${ }^{35}$. Algunos de los instrumentos intervencionistas más rígidos, como el Servicio Nacional del Trigo o el monopolio privado del azúcar continuaron, pero el FORPPA también adoptó nuevas medidas de regulación de los mercados agrarios, muchas basadas en la Política Agraria Común (PAC) de la CEE ${ }^{36}$. El FORPPA

34 La crisis de sobreproducción de 1953, que afectó fundamentalmente a la leche, llevó a Francia a poner en práctica un sistema centralizado de regulación del mercado. La antigua Office du Blé, convertida en Office National Interprofessionnelle des Céréales, se encargó de la regulación del trigo y otros cereales, y se crearon nuevos organismos para otros productos, incluidos la leche y la carne. Estas agencias públicas de regulación se pusieron bajo la dirección del FORMA a principios de los años sesenta. Se intervinieron especialmente los mercados de la leche y los cereales. También se concedieron ayudas oficiales para aumentar la productividad y promover la mecanización y la reforma estructural de las explotaciones, con el objetivo de fomentar la emigración de los agricultores a las ciudades y aumentar sus ingresos. Asimismo, se subvencionaron las exportaciones y se impusieron restricciones e impuestos a las importaciones. Servolin (1989), pp. 95-98; Ingersent y Rayner (1999), p. 143; Klatzmann (1972), p. 42; Sheingate (2001), cap. 4; y Ackrill (2000), p. 25.

35 Para la intervención en el mercado vinícola se había creado en 1953 la Comisión de Compras de Excedentes de Vino, que desapareció en 1968, año en el que el SENPA, organismo ejecutivo del FORPPA, asumió sus funciones.

$36 \quad$ FORPPA (1977), p. 7; y (1986), p. 21. 
intervino en los mercados agrarios a través de subsidios directos a los agricultores, sostenimiento de los precios (precios fijos, de garantía, de sostenimiento y de intervención) y compras públicas de excedentes ${ }^{37}$.

El apoyo al sector se basó, desde los años sesenta, en una gran variedad de medidas de protección comercial o en frontera, ayudas a la producción y, fundamentalmente, regulación de precios. Todas las medidas implementadas entre 1960 y 1975 se resumen en el Cuadro 4. La protección en frontera se centró en el establecimiento de aranceles muy altos para el azúcar (75 por 100 del valor de importación) y el trigo (45 por 100), y más moderados para la cebada y el vacuno (20-25 por 100 a principios de los años setenta) ${ }^{38}$. El proteccionismo también consistió en la aplicación de tasas reguladoras a la importación de varios productos (cereales pienso, semillas oleaginosas, aceites, queso y algunas verduras y frutas), con el objetivo de elevar sus precios hasta el nivel del mercado interior, como los levies de la PAC ${ }^{39}$. La política agraria también consistió en la regulación del mercado mediante el establecimiento de precios de protección de diverso tipo. El precio del azúcar se establecía administrativamente después del acuerdo con los refinadores, y un organismo público compraba a precios fijos la producción de trigo y de tabaco (Servicio Nacional del Trigo y monopolio del tabaco $)^{40}$. Los precios de tasa que se habían fijado durante la autarquía para otros productos se sustituyeron por precios de garantía, de forma que en 1965 sólo el 14 por 100 de la producción estaba sujeta a tasas (trigo, azúcar de caña y remolacha y tabaco). Para otros productos, como los cereales pienso, el arroz, el aceite de oliva y el algodón, se establecieron precios mínimos. El vino disfrutaba de precios de garantía desde 1953, y se extendieron a otros productos desde 1964. En 19661967 se establecieron para los huevos, la carne de aves de corral y el arroz, y se fijaron precios de regulación u orientación para la carne de vacuno. Como consecuencia, el porcentaje de producción sujeta a precios de garantía se incrementó del 36 al 58 por 100 entre 1965 y $1968^{41}$. Estos precios se sostenían en los períodos de sobreproducción o en las cosechas coyunturales abundantes mediante adquisiciones públicas (compras de sostenimiento) y préstamos o ayudas al almacenamiento privado (primas de almacenamiento), en el caso de los cereales pienso, los aceites, el arroz, el vino y los huevos ${ }^{42}$. A principios de los años setenta, el porcentaje de producción

FORPPA (1977), p. 8. OECD (1974) consideró que la política de precios de España se asemejaba a la los países de la CEE.

MAPA (1971).

OECD (1974).

El Servicio Nacional del Trigo garantizaba la compra de toda la producción triguera, lo que tuvo consecuencias financieras desastrosas. Barciela (1981a).

Comisaría del Plan de Desarrollo Económico y Social (1968), p. 35.

FAO (1966), p. 118; y Comisaría del Plan de Desarrollo Económico y Social (1968). 


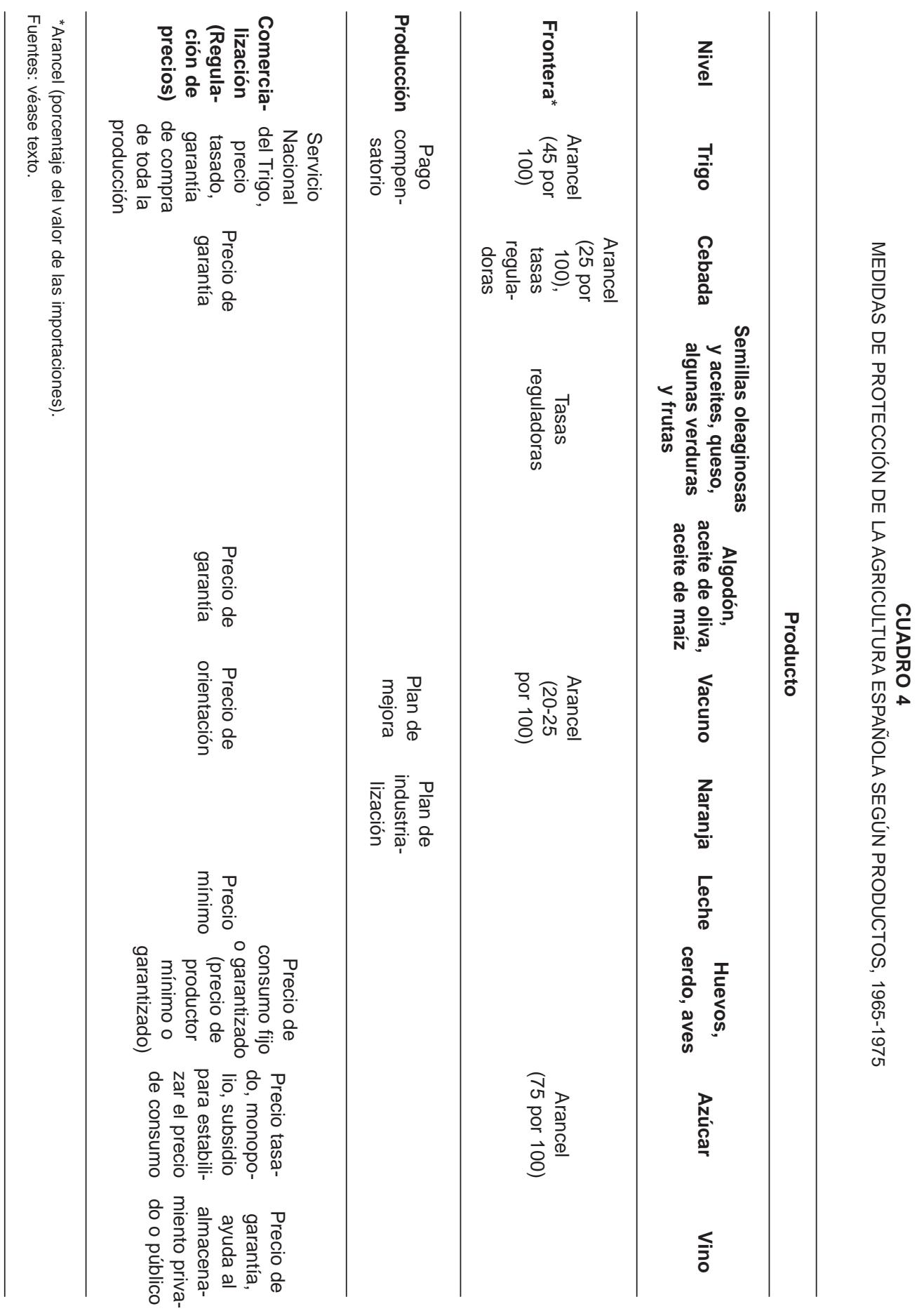


sujeta a precios de garantía alcanzaba el 60 por 100 y llegó a suponer el 64 por 100 a mediados de la década ${ }^{43}$. Además, se fijaron precios fijos de consumo para los productos de demanda creciente (huevos, cerdo y producción avícola) para frenar la escalada de los precios. A los azucareros también se les concedió un subsidio para estabilizar el precio de venta ${ }^{44}$. La cantidad de recursos destinada a garantizar los precios mínimos se multiplicó por cuatro desde 1957, hasta alcanzar 90.000 millones de pesetas en 1966, pero el coste de esta política sólo suponía 19.000 millones de pesetas constantes en $1975^{45}$. Únicamente las frutas y verduras quedaron fuera de la política de garantía de precios ${ }^{46}$. No obstante, se establecieron otras medidas para productos no cubiertos. El FORPPA almacenó patatas y cítricos en los períodos de exceso de producción para prevenir la caída de las cotizaciones. Asimismo, se concedieron subsidios directos para los cítricos y la producción ganadera con el objetivo de fomentar la industrialización y la mejora del proceso productivo (Cuadro 3). La política de precios no sólo intentó estabilizar y sostener los ingresos de los agricultores. Desde finales de los años sesenta, el gobierno también utilizó la regulación del mercado para estimular la producción de cereales pienso y reducir los excedentes de trigo. Con este objetivo, se redujo la tasa del trigo y se introdujo un sistema de precios de orientación para los productores de carne. Estas medidas se complementaron con incentivos a los productores de cebada, pagos a los ganaderos para aumentar el peso de los animales y reducción de los subsidios directos a los trigueros ${ }^{47}$.

En 1970, los precios de sostenimiento o garantía centraban la política agraria en España, como en la CEE y en otros países avanzados. Además, los precios de garantía se fijaron en niveles similares a los de la CEE (Cuadro 5) con el objetivo de impedir las importaciones, excepto en el aceite de oliva y el vino, dos de los principales productos de exportación. A fin de mantener competitivos ambos productos, el precio de garantía se fijó un 50 por 100 más bajo que en la CEE ${ }^{48}$. No obstante, en 1970 el FORPPA soportó un coste de sostenimiento de estos precios inferior al del Fondo Europeo de Orientación y de Garantía Agrícola (FEOGA), organismo regulador de

\footnotetext{
43 Comisaría del Plan de Desarrollo Económico y Social (1972), y Gómez Orbaneja y Checchi (1980). FORPPA (1977).

Calculado a partir de Narváez (1980), p. 139, y FORPPA (1976).

FAO (1966), p. 118, y Comisaría del Plan de Desarrollo Económico y Social (1968).

Gómez Orbaneja y Checchi (1980) y Clar (2005).

Esta política de precios situó al vino y al aceite en el segmento más bajo del mercado internacional, lo que se explica también por otros condicionantes como la falta de marcas y la reducida inversión en publicidad, las escasas economías de escala en la distribución, la estrategia de precios de las empresas, la escasa modernización de las estructuras productivas, la insuficiente homogeneidad del producto o, en el caso del vino, la escasa adaptación de la dotación de factores para el nuevo tipo de vino demandado en el mercado.
} 


\section{CUADRO 5}

PRECIOS GUBERNAMENTALES EN ESPAÑA Y LA CEE, 1970

(pesetas corrientes/kilogramo)

\begin{tabular}{lrrr}
\hline Productos & $\begin{array}{c}\text { España } \\
\text { (a) }\end{array}$ & $\begin{array}{c}\text { CEE } \\
\text { (b) }\end{array}$ & $\begin{array}{c}\text { Ratio } \\
\text { (a)/(b) }\end{array}$ \\
\hline Trigo & 6,7 & 7,1 & 1,0 \\
Cebada & 5,3 & 6,4 & 0,8 \\
Azúcar & 15,3 & 15,8 & 1,0 \\
Vino & 35,0 & 70,5 & 0,5 \\
Leche & 7,6 & 7,6 & 1,0 \\
Huevos & 26,0 & 29,4 & 0,9 \\
Cerdo & 52,9 & 54,1 & 1,0 \\
Vacuno & 36,7 & 47,6 & 1,0 \\
Carne de ave & 38,3 & 36,9 & 1,0 \\
Maíz & 5,7 & 5,6 & 1,0 \\
Arroz & 7,5 & 8,8 & 0,9 \\
Aceite de oliva & 34,5 & 80,7 & 0,4 \\
\hline
\end{tabular}

Fuentes: MAPA (1971), anexo 26.

la PAC (Cuadro 6). El coste suponía sólo un 5 por 100 del valor de la producción agraria en España, un tercio menos que en la CEE. El gasto por agricultor sumaba en promedio 4.000 pesetas, cantidad que constituía solamente un 25 por 100 del de la Comunidad y apenas un 20 por 100 por explotación y hectárea.

\section{El sostenimiento de la renta de los agricultores españoles en pers- pectiva internacional, 1960-1975}

La política agraria cambió sustancialmente desde los años sesenta, pero ¿consiguieron los agricultores españoles el mismo apoyo que en países democráticos? Para evaluar el grado de protección alcanzado en España en perspectiva internacional, se ha calculado el Coeficiente de Protección Nominal (en adelante, CPN), o ratio del precio doméstico y el precio mundial, para doce productos. Datos comparables para Europa occidental y otros países avanzados se encuentran en el trabajo de Anderson, Hayami y Honma (1989, p. 27). El Cuadro 7 resume el CPN en España entre 1955 y 


\section{CUADRO 6}

COSTE ANUAL DE LAS POLÍTICAS AGRARIAS EN ESPAÑA Y LA CEE, 1970

(pesetas corrientes)

\begin{tabular}{lrr}
\hline & España & \multicolumn{1}{c}{ CEE } \\
\hline Por agricultor & 3.788 & 16.397 \\
Por hectárea & 319 & 2.313 \\
Por explotación & 5.176 & 26.746 \\
Porcentaje del valor de la producción & 4,6 & 7,6 \\
\hline
\end{tabular}

Fuentes: MAPA (1971), p. 10.

1980, correspondiendo a la CEE las cifras entre paréntesis. Como estos autores, para calcular el precio interno se han utilizado las cotizaciones de cada producto en la producción con el objetivo de reflejar las políticas de apoyo a los precios ${ }^{49}$. Para el precio del mercado internacional, se ha recurrido a los precios de importación, excepto para el vino y las naranjas, para los que se han empleado los de exportación ${ }^{50}$.

Como se observa en el Cuadro 7, en 1960 el CPN alcanzaba en España niveles similares a los de la CEE para la mayoría de los productos. Desde entonces, como en la Europa avanzada, el grado de protección comenzó a ascender, especialmente para los cereales, los huevos, las patatas y la leche ${ }^{51}$. Esta tendencia finalizó a mediados de los años setenta, como consecuencia de la crisis mundial, que elevó de forma extraordinaria el precio internacional respecto al del mercado interno. Para contrarrestar este aumento, los precios de garantía se elevaron en España entre 1972 y 1975. Solamente en 1975, el precio administrativo del azúcar y el precio de garantía de la leche se incrementaron un 38 y un 26 por 100, respectivamente ${ }^{52}$. Sin embargo, estos aumentos fueron insuficientes, por lo que el CPN cayó sustancialmente en 1975 para todos los productos y este descenso continuó hasta 1980, lo que también ocurrió, aunque en menor grado, en la CEE. Los datos del CPN indican, por otra parte, que la protección no se centró exclusivamente en el trigo. El azúcar y el vino recibieron más protección, y los CPN de la cebada y de los huevos alcanzaron niveles similares

49

Los precios de producción de Barciela et al. (2005) se han complementado con los del Anuario de Producciones Agrícolas.

50 Los precios de importación/exportación se han calculado como la ratio de los valores y la producción, datos obtenidos en el Anuario de Comercio Exterior.

51 En Europa occidental y los países del este asiático, esta tendencia en el grado de protección se había iniciado antes. Anderson, Hayami y Honma (1986), pp. 26-27.

52 FORPPA (1986), p. 21. 


\section{CUADRO 7}

COEFICIENTE DE PROTECCIÓN NOMINAL SEGÚN PRODUCTOS EN ESPAÑA Y LA CEE, 1955-1980*

\begin{tabular}{lcccccc}
\hline & Trigo & Cebada & Azúcar & Vino & Naranjas & Leche \\
\hline $\mathbf{1 9 6 0}$ & $1,3(1,4)$ & $1,2(1,3)$ & $2,6(2,0)$ & 6,8 & s.d. & $0,4(1,3)$ \\
$\mathbf{1 9 6 5}$ & $1,7(1,4)$ & $1,2(1,2)$ & $1,5(1,9)$ & 7,1 & 2,0 & $1,3(1,4)$ \\
$\mathbf{1 9 7 0}$ & $1,8(1,5)$ & $2,0(1,7)$ & $1,5(1,9)$ & 2,7 & 1,5 & $1,1(1,9)$ \\
$\mathbf{1 9 7 5}$ & $0,6(1,1)$ & $0,8(1,1)$ & $0,7(0,7)$ & 4,7 & 2,1 & $0,7(1,6)$ \\
$\mathbf{1 9 8 0}$ & $1,0(1,2)$ & $1,1(1,2)$ & s.d. & s.d. & s.d. & $1,4(1,4)$ \\
\hline & Huevos & Tabaco & Algodón & Vacuno & Cerdo & Patatas \\
\hline $\mathbf{1}$ & \multirow{2}{*}{$\mathbf{1 9 6 0}$} & s.d. & 0,4 & s.d. & $0,4(1,3)$ & 0,9 \\
$\mathbf{1 9 6 5}$ & $0,8(1,2)$ & 0,6 & 0,4 & $0,6(1,7)$ & $0,6(1,4)$ & 1,1 \\
$\mathbf{1 9 7 5}$ & $1,9(1,2)$ & 0,4 & 0,4 & $0,7(1,8)$ & $0,7(1,2)$ & 0,8 \\
$\mathbf{1 9 8 0}$ & $1,1(1,1)$ & 0,8 & 0,5 & $0,7(1,6)$ & $0,9(1,2)$ & 0,4 \\
\hline
\end{tabular}

(*) Entre paréntesis los datos correspondientes a la CEE; s.d.= sin datos.

Fuentes: Anuario de Producciones Agrícolas, Barciela et al. (2005) y Anuario de Comercio Exterior, para España; para la CEE, Anderson, Hayami y Honma (1989), p. 27.

a los del trigo. Por el contrario, en 1965, 1970 y 1975, el grado de protección para la carne de vacuno y porcino fue significativamente inferior en España, pero, en perspectiva internacional, los CPN del trigo y de la cebada alcanzaron en nuestro país un nivel similar al de la CEE.

El CPN no tiene en cuenta los subsidios transferidos a los agricultores y otras políticas agrarias que no afectan a los precios, pero que tienen un impacto significativo en los ingresos relativos de aquéllos. Como medida alternativa de la protección se ha calculado el indicador que la OCDE emplea desde 1989, el Producer Support Estimate (en adelante, PSE), más adecuado para evaluar las políticas agrarias, porque recoge todos los instrumentos públicos de apoyo al sector ${ }^{53}$. Las comparaciones internacionales con el PSE son, sin embargo, más complicadas, puesto que sólo se dispone de este indicador, en el período anterior a 1980, para Bélgica ${ }^{54}$. El PSE se define como el valor de las transferencias brutas anuales desde los consumidores y 
CUADRO 8

PRODUCER SUPPORT ESTIMATE COMO PORCENTAJE DEL VALOR DE LA PRODUCCIÓN, 1955-1975

\begin{tabular}{lrrrrr}
\hline & Trigo & Cebada & Azúcar & Vino & Naranjas \\
\hline 1960 & 25 & 21 & 64 & 97 & \\
1965 & 45 & 21 & 37 & 109 & 49 \\
1970 & 53 & 56 & 35 & 98 & 36 \\
1975 & -65 & -14 & -27 & 87 & 55 \\
\hline & Leche & Huevos & Vacuno & Porcino & Patatas \\
\hline 1960 & & 5 & & & -7 \\
1965 & 21 & -24 & -57 & -75 & -32 \\
1970 & 8 & 47 & -37 & -52 & \\
1975 & -46 & 11 & -88 & & \\
\hline
\end{tabular}

Fuentes: véase el texto.

contribuyentes a los productores a través de todas las políticas de sostenimiento de rentas. El PSE es la suma del Market Price Support (MPS) y de una gran variedad de diferentes ayudas o transferencias monetarias: subsidios, deficiency payments o ayudas a la compras de inputs. El MPS, el principal instrumento de apoyo a los agricultores en los países desarrollados en la actualidad, recoge el efecto de todas las políticas que crean una diferencia entre el precio doméstico y el internacional, desde la protección comercial y la restricción de las importaciones, a las políticas de precios o el almacenamiento de los excedentes. El MPS se define como:

$$
\mathrm{MPS}=(\mathrm{PD}-\mathrm{PW})^{*} \mathrm{Q}
$$

donde PD, PW y Q representan el precio de producción, el precio mundial y la producción, respectivamente ${ }^{55}$. Al MPS se han sumado todas las transferencias moneta-

55 La OCDE clasifica todas las transferencias según el criterio de implementación, no por sus objetivos o consecuencias. La clasificación de la OCDE asociada al PSE consiste en "Market Price Support; Payments based on output, area planted or animal numbers; Historical Entitlements; Input Use; Input Constraints; Overall Farming Income y Miscellaneous payments". La OCDE presentó por primera vez el PSE en 1999 en su informe anual Agricultural Policies in OECD countries: Monitoring and Evaluation. Antes de 1999 este indicador se denominaba Producer Subsidy Equivalent (OECD, 2002b); sobre los fundamentos teóricos, Corden (1971); Josling (1973 y 1975), acuñó el término Producer Subsidy Equivalent y lo utilizó para calcular el grado de protección a la agricultura. Sobre el método de cálculo, véase también Cahill y Legg (1990). 
rias, asignadas a cada producto según su peso en los subsidios y las transferencias totales (obtenido en FORPPA, 1977, p. 7; y MAPA-UAM, 1977). Los resultados para los doce productos se muestran en el Cuadro 8, en el que el PSE se presenta como porcentaje del valor de la producción agraria (en adelante, \%PSE).

El \%PSE confirma los resultados obtenidos por el CPN. Según este indicador, el grado de protección alcanzó niveles positivos para los cereales, el azúcar y el vino en 1960. El \%PSE para el azúcar disminuyó desde el 64 por 100 al 37 por 100 entre 1960 y 1965, y después se mantuvo en un 35 por 100, mientras que en Bélgica llegó casi al 60 por 100 en el mismo período. Para el trigo, el \%PSE promedio en los años sesenta fue tan alto en España (35 por 100) como en Bélgica (34 por 100). Lo mismo ocurrió para la cebada, cuyo \%PSE alcanzó un 25 por 100 en Bélgica y un 21 por 100 en España. Por otra parte, este indicador llegó a niveles extraordinariamente altos para el vino (casi un 100 por 100) y las naranjas (50 por 100$)^{56}$. El alto grado de protección para ambos productos provenía de los subsidios a la exportación, que crearon una diferencia positiva entre el precio interior y el de exportación. Por último, frente al elevado nivel de protección de la carne de vacuno y porcino en Bélgica durante los años sesenta y setenta (36 por 100 y 7 por 100), en España el \%PSE para ambos productos era insignificante o negativo (excepto en 1970).

Según el CPN y el PSE, por tanto, el apoyo a la agricultura afectó esencialmente a los productores de cereales, vino y azúcar, mientras que la protección de la carne y otros productos alcanzó niveles bajos en España en comparación con Bélgica y otros países de la Europa avanzada. Como consecuencia de la protección negativa que recibió la carne de vacuno y porcino, el grado de apoyo al sector fue inferior en España que en la Europa avanzada, aunque sólo existen datos comparables para otros países para finales de la década de 1970. El \%PSE total para España, calculado como la suma del PSE de todos los productos del Cuadro 8 (que suman 60-65 por 100 del valor de la producción agraria total) ponderados por el peso de cada uno en el valor total de la producción, alcanzó sólo un 14-15 por 100 en 1960 y 1965 y un 9 por 100 en 1970. En la CEE la protección se elevó al 35 por 100 en 1979-1981 ${ }^{57}$. Los diferentes grados de protección de los productos causaron distorsiones en la asignación de recursos dentro de la agricultura y la protección a los productores de trigo generó excedentes cuantiosos, con costes crecientes de almacenamiento ${ }^{58}$. Pero esta situa-

\footnotetext{
56 En los años setenta el sector de los cítricos tendió a tener excedentes, MAPA (1971), p. 7.

57 Fanfani (1998). En 1986-1988, el apoyo a los agricultores de la OCDE alcanzó niveles significativamente mayores que en períodos anteriores. Según OECD (2002a), el PSE para Estados Unidos, Japón, la Unión Europea y todos los países de la OCDE significaba el 42, 62, 25 y 38 por 100, respectivamente, del valor de la producción agraria.

58 Barciela (1986); Barciela et al. (2001); Tamames (1965).
} 
ción no fue exclusiva de España. Los excesos de producción y el alto coste del almacenamiento público o privado de los excedentes se dieron con frecuencia en Francia, Estados Unidos y otros países ${ }^{59}$. En estas economías, ciertos productos recibieron niveles similares de protección, lo que se explica porque las políticas agrarias están influenciadas por las características de cada producto o cultivo ${ }^{60}$. Los programas públicos de protección asistieron fundamentalmente a los productos con baja elasticidad precio de oferta o demanda y a los productos importables, mientras que algunas producciones (como los productos hortofrutícolas) apenas recibieron ayudas ${ }^{61}$. Por ejemplo, en 1999-2001 el PSE promedio de los países de la OCDE ascendió al 20 por 100 para la lana y los huevos, al 20 y 35 por 100 para el maíz, los aceites y la carne, pero al 40-50 por 100 para el trigo, la leche, el azúcar y el arroz ${ }^{62}$.

Por otra parte, según la OCDE, los efectos de las transferencias y las políticas de apoyo a la economía y al bienestar general dependen de la forma en que se implementaban. Las políticas que crean una diferencia entre el precio del mercado interno y el internacional (esencialmente el MPS y las transferencias basadas en la producción) constituyen las formas más distorsionadoras de proteger a la agricultura ${ }^{63}$. En España, las políticas agrarias con efectos más negativos (MPS) suponían un 90 por 100 del apoyo a los agricultores y este porcentaje se mantuvo alto en todo el perío$\mathrm{do}^{64}$. No obstante, el porcentaje es sólo ligeramente superior al de los países de la OCDE para un período posterior, donde la importancia del MPS y de los pagos basados en el output ascendía al 82 por 100 en 1986-1988. En Corea y Japón, esta forma de apoyo llegó a significar el 98 por 100 del total en los años ochenta ${ }^{65}$.

No obstante, para evaluar correctamente las políticas agrarias es necesario cuantificar la pérdida neta de bienestar que ocasionaron (deadweight loss), o diferencia entre los beneficios que obtuvieron los agricultores y la pérdida en bienestar general ${ }^{66}$. Según Barceló (1983, p. 68), el coste social de la protección en España ascendió al 0,5 por 100 del PIB en 197967. Para la CEE, Spencer (1985) habla de una disminución en bienestar de aproximadamente un 1 por 100 del PIB hacia 1980, mientras que,

Ackrill (2000), y Andreosso-O'Callaghan (2003). Los contribuyentes pagaban el coste de almacenar los excedentes, lo que incrementaba los deadweight losses (la diferencia entre los beneficios que obtuvieron los agricultores y la pérdida en bienestar general) y reducía el bienestar general en los países avanzados (Federico, 2005).

60 Hoffman y Libecap (1991).

61 Para el caso de Estados Unidos, véanse Gardner (1987 y 1992).

62 OECD (2002a), p. 28.

63 OECE (2002a), pp. 13-14.

64 Calculado con los datos del Cuadro 8.

65 OECD (2002a).

$66 \quad$ Federico (2005), p. 188.

67 No obstante, los resultados dependen de la metodología utilizada. Winters (1987). 
para mediados de los años ochenta, Gardner (1986) cifra las pérdidas en Estados Unidos en un 0,1 por $100^{68}$. Algunos de los costes de la intervención de la agricultura en España provinieron probablemente de la capacidad presupuestaria restringida y del número bajo de empleados públicos en las agencias de regulación. Un aumento mayor de la productividad y de los ingresos necesitaba de un incremento más acelerado del gasto público, con el objetivo de apoyar la mecanización y la introducción de otras innovaciones tecnológicas, pero esta política no se pudo abordar hasta la reforma fiscal de la España democrática (y la llegada de los fondos de la PAC desde finales de los años ochenta). La restricción presupuestaria provocó que gran parte de la protección a los agricultores se obtuviera a través de la regulación del mercado y no mediante transferencias directas (como en Estados Unidos, por ejemplo). Parte de las consecuencias negativas se produjeron probablemente por la falta de información sobre los precios, los stocks o el volumen de la demanda, una información que debían reunir los agentes oficiales para poder regular los mercados. Pero en España el número de funcionarios (de la Administración Central) se mantuvo estancado durante todo el régimen franquista ${ }^{69}$.

\section{La escasa ventaja comparativa del sector como factor del apoyo a los agricultores}

El modelo del developmental pattern no explica por qué países avanzados como Australia, Nueva Zelanda o Canadá, con porcentajes muy bajos de población agraria, no desarrollaron políticas de protección a los agricultores ${ }^{70}$; mientras que la protección aumentó en países relativamente pobres, con sectores agrarios relativamente amplios, como en Japón durante el período de entreguerras o en Corea del Sur en los años sesenta ${ }^{71}$. Según Anderson y Hayami (1986), las diferencias en el grado de protección en los países avanzados se pueden explicar por la ventaja comparativa en agricultura. Japón o Corea del Sur adoptaron políticas de apoyo a los agricultores

\footnotetext{
68 Bale y Lutz (1981) calcularon que las pérdidas en bienestar en 1976 supusieron el 0,1 por 100 del PIB en Francia, el 0,2 por 100 en Alemania y el 0,7 por 100 en Japón.

69 Durante el franquismo, el número de empleados del Ministerio de Agricultura se mantuvo estancado en torno a 5.000. En 1960 había un funcionario por cada 920 agricultores, en 1965 y 1970 uno por casi 800 y en 1975, 599 (calculado a partir de Jordana y Ramió, 2005, p. 1005). Por el contrario, en Estados Unidos, había un empleado de la USDA por cada 330 productores antes de 1930 y uno por cada 22 en los años sesenta (Libecap, 1998, p. 208).

70 De Gorter y Tsur (1991), y Anderson (2006).

71 Anderson (2006).
} 


\section{CUADRO 9}

LABOUR-PRODUCTIVITY RATIO EN ESPAÑA Y EN CINCO PAÍSES INDUSTRIALES, 1955-1980

\begin{tabular}{lcccccc}
\hline & España & $\begin{array}{c}\text { Estados } \\
\text { Unidos }\end{array}$ & Japón & Francia & Alemania & Italia \\
\hline $\mathbf{1 9 5 8}$ & 50,7 & 51,7 & 23,3 & 37,2 & 41,3 & 22,3 \\
$\mathbf{1 9 6 0}$ & 56,8 & 65,2 & 22,5 & 38,0 & 40,7 & 22,6 \\
$\mathbf{1 9 6 5}$ & 37,1 & 69,7 & 20,4 & 42,3 & 44,4 & 27,4 \\
$\mathbf{1 9 7 0}$ & 35,1 & 80,2 & 18,2 & 44,9 & 54,1 & 26,5 \\
$\mathbf{1 9 7 5}$ & 23,3 & 100,0 & 18,3 & 47,4 & 54,2 & 28,2 \\
$\mathbf{1 9 8 0}$ & 16,2 & 128,7 & 18,2 & 55,6 & 62,6 & 33,2 \\
\hline
\end{tabular}

Fuentes y método de cálculo: Anderson (1986); para España, véase nota 73.

más temprano y con el tiempo alcanzaron mayores niveles de protección, debido a su escasa ventaja en la producción agraria ${ }^{72}$. En esta sección se considera que el aumento de la protección a los agricultores españoles desde los años sesenta se debió también a este factor. Para comprobar esta hipótesis se ha utilizado el mismo indicador que utilizan Anderson y Hayami, el labour-productivity ratio (en adelante, LPR), que mide la productividad relativa del trabajo agrario, expresada como porcentaje de la de Estados Unidos, así como el déficit de la balanza comercial agraria ${ }^{73}$. Como se muestra en el Cuadro 9, la LPR disminuyó más de un 50 por 100 en España entre 1960 y 1975. Durante este periodo, solamente Japón experimentó un declive similar, mientras que los países europeos y Estados Unidos mostraron una tendencia ascendente. En 1975, la LPR de España representaba un 23 por 100 de la de Estados Unidos, sólo comparable con la de Italia (28 por 100) y Japón (18 por 100), mientras que la de Francia y Alemania alcanzaron prácticamente el doble (48 y 54 por 100, respectivamente).

Puesto que el crecimiento económico disminuye la ventaja comparativa en agricultura, la tesis de Anderson y Hayami explica por qué los mayores niveles de protección aparecen entre los países avanzados. La protección en Asia oriental fue superior a la de Australia, Nueva Zelanda y Estados Unidos, países con mayor ventaja comparativa en agricultura (Honma y Hayami, 1986).

73 La productividad del trabajo agrario se ha calculado como la producción total medida en unidades de trigo dividida por el número de agricultores. La producción total se ha trasformado en unidades de trigo dividiendo el valor de la producción total por los precios de este producto. Los datos se han obtenido en Barciela et al. (2005) y Anuario de Producciones Agrarias. La productividad del trabajo industrial se ha tomado de Prados (2003). Ambas productividades se han convertido a dólares de Estados Unidos con los datos de Martín Aceña y Pons (2005) y se han transformado en un índice relativo a las productividades de Estados Unidos de 1975. La LPR se ha obtenido dividiendo ambos índices. 


\section{GRÁFICO 3}

BALANZA COMERCIAL EXTERNA DE LA AGRICULTURA ESPAÑOLA, 1964-1989

(miles de millones de pesetas constantes)

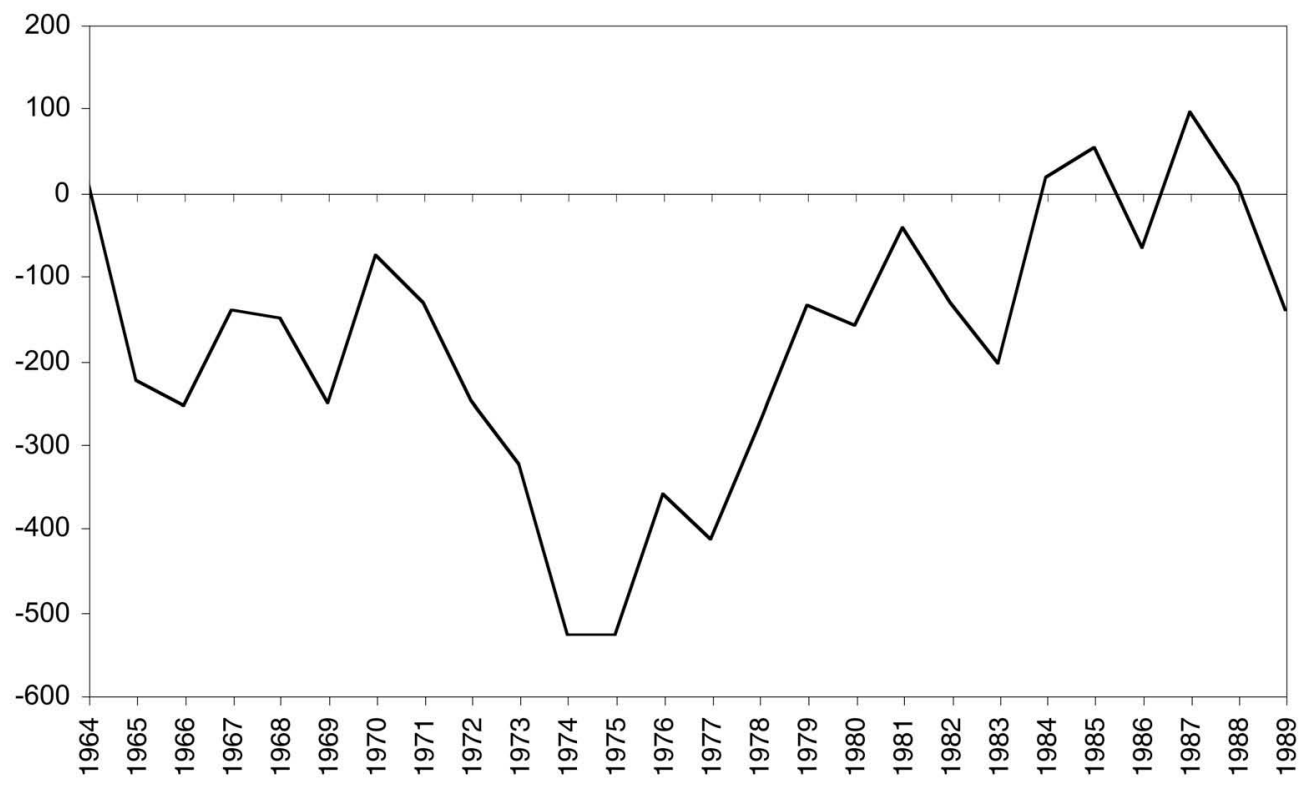

Fuentes: Estadísticas de Comercio Exterior (varios años) y Carreras et al. (2005).

La baja ventaja comparativa en agricultura de España se reflejó en la creciente dependencia en importaciones de alimentos ${ }^{74}$. El crecimiento económico y el cambio en la estructura de consumo provocaron un aumento considerable de las importaciones de productos agrarios desde 1965. A pesar del aumento de las exportaciones ${ }^{75}$, el déficit comercial en la balanza exterior agraria aumentó sustancialmente (Gráfico 3) y en 1967 llegó a representar el 8 por 100 del déficit comercial total ${ }^{76}$, a pesar de que la política desarrollada desde finales de los años sesenta estimuló la sustitución de cereales de consumo humano por cebada y el desarrollo de la ganadería intensiva.

\footnotetext{
74 La dependencia creciente de alimentos importados durante el proceso de desarrollo económico también fue habitual en otros países con escasa ventaja comparativa en agricultura, como los de Asia oriental (Anderson, 1986).

75 Véase nota 24.

76 Comisaría del Plan de Desarrollo Económico y Social (1968).
} 


\section{CUADRO 10}

PROMEDIO ANUAL DE IMPORTACIONES DE ALIMENTOS EN ESPAÑA, 1940-1983

(miles de toneladas)

\begin{tabular}{lrrrrr}
\hline & Trigo & Maíz & Carne & Cebada & Leche \\
\hline $\mathbf{1 9 4 0 - 1 9 4 4}$ & 448 & 71 & 1 & 25 & - \\
$\mathbf{1 9 4 5 - 1 9 4 9}$ & 326 & 15 & 13 & 22 & - \\
$\mathbf{1 9 5 0 - 1 9 5 4}$ & 342 & 11 & 1 & 31 & 0 \\
$\mathbf{1 9 5 5 - 1 9 5 9}$ & 59 & 61 & 21 & 59 & 1 \\
$\mathbf{1 9 6 0 - 1 9 6 4}$ & 452 & 547 & 42 & 334 & 13 \\
$\mathbf{1 9 6 5 - 1 9 6 9}$ & 49 & 2.244 & 122 & 317 & 43 \\
$\mathbf{1 9 7 0 - 1 9 7 4}$ & 45 & 2.646 & 119 & 73 & $\mathbf{7 2}$ \\
$\mathbf{1 9 7 5 - 1 9 7 9}$ & 151 & 4.114 & 58 & 659 & 37 \\
$\mathbf{1 9 8 0 - 1 9 8 4}$ & 186 & 4.392 & & & 4 \\
\hline
\end{tabular}

Fuentes: Barciela et al. (2005).

La producción de cereales pienso se incrementó rápidamente desde mediados de los años sesenta ${ }^{77}$. Los cambios en el marco del II Plan de Desarrollo supusieron un declive en la superficie dedicada al trigo de más de 500.000 hectáreas, mientras que las de cebada y de maíz crecieron en 600.000 hectáreas y 125.000 hectáreas, respectivamente. La producción de vacuno se incrementó en 300.000 toneladas, más de lo que se había planeado en el II Plan ${ }^{78}$. Sin embargo, España continuó dependiendo de las importaciones de animales vivos, carne y piensos (Cuadro 10). Aunque la importancia de la ganadería en la producción final agraria se incrementó desde un 31 por 100 a mediados de los años cincuenta al 40 por 100 en 1970, este porcentaje se mantuvo estable durante los años setenta ${ }^{79}$. La producción de forraje se cuadriplicó, pero continuó siendo insuficiente. El output de maíz se mantuvo por debajo de las necesidades internas, por lo que parte de la demanda se tuvo que cubrir con importaciones. Las compras de cereales pienso en el mercado internacional se mantuvieron en niveles elevados y llegaron a suponer la mitad de las importaciones. Las compras de leche también aumentaron ${ }^{80}$. Las importaciones de carne disminuyeron desde 1970, pero se mantuvieron elevadas (Cuadro 10).

\footnotetext{
77 Clar (2005).

78 MAPA (1971), p. 9. Sobre la ganadería, véanse Domínguez Martín (2001) y Simpson (1995).

79 Barciela et al. (2005).

$80 \quad$ OECD (1974), p. 16.
} 


\section{Conclusiones}

Con datos de doce productos, este artículo ha examinado en perspectiva internacional el grado de protección de las rentas de los agricultores españoles durante el franquismo, con el objetivo de comprobar la hipótesis de Lindert (1991) de que los agricultores consiguen mayor protección si viven en países democráticos. El artículo constata que el apoyo a los agricultores en España aumentó desde la década de 1960, cuando el país experimentó un proceso de rápido crecimiento económico. La transferencia de subsidios aumentó y las políticas de sostenimiento de precios y de intervención del mercado se extendieron a multitud de productos. Más aún, según el Coeficiente de Protección Nominal (CPN) y el Producer Support Estimate (PSE), la protección alcanzó en España niveles similares a los de la CEE. El aumento de la protección se debió al declive del peso del sector en la economía, que eliminó la resistencia del sector urbano a incrementar las transferencias a los agricultores, aunque pueden tenerse en cuenta otros factores, como la necesidad del régimen de prevenir desórdenes sociales en el campo, en un período de fuerte inestabilidad social y política. La protección provino fundamentalmente de la regulación del mercado y la política de precios, por lo que los desembolsos presupuestarios fueron escasos y disminuyeron progresivamente como consecuencia de la caída del número de agricultores. Según el CPN y el PSE, desde los años sesenta el trigo, la cebada, el azúcar, el vino y las naranjas obtuvieron los niveles de protección más elevados y alcanzaron niveles similares a los conseguidos por los mismos productos en otros países europeos. El elevado nivel de apoyo desde 1960, especialmente a los productores trigueros, no fue excepcional en España. La protección y sostenimiento de las rentas se dieron también en otros países avanzados, lo que se puede explicar por el proceso de industrialización y por la pérdida de ventaja comparativa en agricultura. No obstante, el nivel de apoyo general de la agricultura alcanzó niveles inferiores en España debido a que la carne de vacuno y de porcino, muy protegidas en otros países, apenas recibieron apoyo a través de los precios por la alta elasticidad de la demanda de estos productos en los años sesenta y setenta.

Por último, los resultados de este estudio han determinado que los factores económicos (el rápido proceso de crecimiento económico, la caída del peso del sector en la economía y el descenso de los precios relativos de la agricultura) prevalecieron en la determinación de los niveles de protección en España, hecho que contradice la idea de que sólo los países democráticos desarrollan políticas de transferencia de rentas a los agricultores y de sostenimiento de sus ingresos. En conexión con la teoría de Anderson y Hayami, la elevada protección se debió a la escasa ventaja de España en agricultura, que se plasmó en la baja productividad relativa del trabajo agrario y en el cuantioso y creciente déficit comercial del sector. Con el crecimiento económico, España dependió de las importaciones por la dificultad del sector en 
cambiar su especialización tradicional al mismo ritmo que se modificaba la demanda de productos agrarios.

\section{Bibliografía}

ACKRILL, Robert (2000): The Common Agricultural Policy, Sheffield, Sheffield Academic Press.

ANDERSON, Kym (1986): "Economic Growth, Structural Change and the Political Economy of Protection", en ANDERSON, Kym, y HAYAMI, Yujiro (eds.), The Political Economy of Agricultural Protection: East Asia in International Perspective, Sydney, Allen and Unwin, pp. 7-16.

-(1995): “Lobbying incentives and the pattern of protection in rich and poor countries", Economic Development and Cultural Change, 43 (2), pp. 401-423.

-(2006): "Reducing distortions to agricultural incentives: Progress, pitfalls, and prospects", American Journal of Agricultural Economics, 88 (5), pp. 1135-1146.

ANDERSON, Kym, y HAYAMI, Yujiro (1986) (eds.): The Political Economy of Agricultural Protection: East Asia in International Perspective, Sydney, Allen and Unwin.

ANDERSON, Kym; HAYAMI, Yujiro, y HONMA, Masayoshi (1986): "The Growth of Agricultural Protection", en ANDERSON, Kym, y HAYAMI, Yujiro (eds.), The Political Economy of Agricultural Protection: East Asia in International Perspective, Sydney, Allen and Unwin, pp. 17-31.

ANDREOSSO-O'CALLAGHAN, Bernadette (2003): The Economics of European Agriculture, Basingstoke, Palgrave.

BALE, Malcolm D., y LUTZ, Ernst (1981): "Price distortions in agriculture and their effects: an international comparison", American Journal of Agricultural Economics, 63, pp. 8-22.

BARCELÓ, Luis Vicente (1983): “Coste social y efectos redistributivos de la protección económica de la agricultura", Papeles de Economía Española, 16, pp. 57-83.

BARCIELA, Carlos (1981a): La financiación del Servicio Nacional del Trigo, Madrid, Banco de España.

—(1981b): "El estraperlo del trigo en la posguerra", Moneda y Crédito, 159, pp. 17-37.

-(1985): "Intervencionismo y crecimiento agrario en España, 1936-1971", en MARTÍN ACEÑA, Pablo, y PRADOS DE LA ESCOSURA, Leandro (eds.), La Nueva Historia Económica en España, Madrid, Tecnos, pp. 285-316.

-(1986): “Los costes del franquismo en el sector agrario: la ruptura del proceso de transformaciones. Introducción", en GARRABOU, Ramón; BARCIELA, Carlos, y JIMÉNEZ-BLANCO, José Ignacio (eds.), Historia agraria de la España contemporánea, 3. El fin de la agricultura tradicional (1900-1960), Madrid, Crítica, pp. 383454 . 
-(1987): "Crecimiento y cambio en la agricultura española desde la guerra civil", en

NADAL, Jordi; CARRERAS, Albert, y SUDRIÀ, Carles (comps.), La economía española en el siglo XX, Barcelona, Ariel, pp. 258-279.

-(1994): "Fraude fiscal y mercado negro durante el primer franquismo", Hacienda

Pública Española, 1, pp. 367-381.

-(1997): "Modernización de la agricultura y política agraria", Papeles de Economía Española, 73, pp. 112-133.

-(2003a): Autarquía y mercado negro: El fracaso económico del primer Franquismo, 19391959, Barcelona, Crítica.

-(2003b): "El lobby agrario en la España franquista", en SÁNCHEZ, Glicerio, y TASCÓN, Julio (eds.), Los empresarios de Franco. Política y economía en España, 1936-1957, Barcelona, Crítica, pp. 111-120.

-(2007): "Ni un español sin pan". La Red Nacional de Silos y Graneros, Zaragoza, Prensas Universitarias de Zaragoza.

BARCIELA, Carlos; MELGAREJO, Joaquín, y LÓPEZ, Inmaculada (1996): “La intervención del Estado en la agricultura durante el siglo XX", Ayer, 21, pp. 51-96.

BARCIELA, Carlos; LÓPEZ, Inmaculada; MELGAREJO, Joaquín, y MIRANDA, José Antonio (2001): La España de Franco (1939-1975), Madrid, Síntesis.

BARCIELA, Carlos; GIRÁLDEZ, Jesús; GRUPO DE ESTUDIOS DE HISTORIA RURAL, y LÓPEZ, Inmaculada (2005): "Sector agrario y pesca", en CARRERAS, Albert, y TAFUNELL, Xavier (coords.), Estadísticas Históricas de España, siglos XIX y XX, Bilbao, Fundación BBVA, pp. 245-356.

BATES, Robert H. (1983): "Patterns of Market Intervention in Agrarian Africa", Food Policy, 8, pp. 297-304.

BECKER, Gary S. (1983): “A Theory of Competition among Pressure Groups for Political Influence", The Quarterly Journal of Economics, 98 (3), pp. 371-400.

BEGHIN, John, y KHERALLAH, Mylène (1994): "Political institutions and international of agricultural protection", The Review of Economics and Statistics, 76 (3), pp. 482-489.

BINSWANGER, Hans P., y DEININGER, Klaus (1997): “Explaining Agricultural and Agrarian Policies in developing Countries", Journal of Economic Literature, 35 (4), pp. 1958-2005.

BOSQUE MAUREL, Joaquín (1984): “Del INC al IRYDA: análisis de los resultados obtenidos por la política de colonización posterior a la Guerra Civil", Agricultura y Sociedad, 32, pp. 153-191.

CAHILL, Carmel, y LEGG, Wilfrid (1990): "Estimation of Agricultural Assistance using Producer and Consumer Subsidy Equivalents: theory and practice", OECD Economic Studies (http://wwww.oecd.org/dataoecd/63/26/34315829.pdf).

CARRERAS, Albert; PRADOS, Leandro, y ROSÉS, Joan (2005): “Renta y Riqueza", en CARRERAS, Albert, y TAFUNELL, Xavier (coords.), Estadísticas Históricas de España, siglos XIX y XX, Bilbao, Fundación BBVA, pp. 1297-1397. 
CERCÓS, Alberto (1983): “La política agraria en la década de los sesenta", Papeles de Economía Española, 16, pp. 302-312.

CLAR, Ernesto (2005): “Del cereal alimento al cereal pienso. Historia y balance de un intento de autosuficiencia ganadera: 1967-1972", Historia Agraria, 37, pp. 513544.

COMISARÍA DEL PLAN DE DESARROLLO ECONÓMICO Y SOCIAL (1968): II Plan de desarrollo económico y social: agricultura, Madrid.

-(1972): III Plan de desarrollo económico y social: agricultura, Madrid.

CORDEN, Warner Max (1971): The Theory of Protection, London, Oxford University Press.

DE GORTER, Harry, y SWINNEN, Johan (2002): “Political Economy of Agricultural Policy", en GARDNER, Bruce L., y RAUSSER, Gordon C. (eds.), Handbook of Agricultural Economics, vol. 2, pp. 1893-1943.

DE GORTER, Harry, y TSUR, Yacov (1991): “Explaining price Policy bias in agriculture: the calculus of support-maximizing politicians", American Journal of Agricultural Economics, 73, pp. 1244-1254.

DOMÍNGUEZ MARTÍN, Rafael (2001): “La ganadería española: del franquismo a la CEE. Balance de un sector olvidado", Historia Agraria, 23, pp. 39-52.

FANFANI, Roberto (1998): Lo sviluppo della politica agricola comunitaria, Roma, Carocci. FAO (1966): The Development of agriculture in Spain; report of a mission organized by the International Bank for Reconstruction and Development and the Food and Agriculture Organization of the United Nations at the request of the Government of Spain, Washington, FAO.

FEDERICO, Giovanni (2005): Feeding the World. An Economic History of Agriculture, 1800-2000, Princeton, Princeton University Press.

FORPPA (1977): Actuación del FORPPA: Evolución pasada y previsión para 1978, Madrid, MAPA.

-(1986): Los precios de los nuevos productos regulados, 1976-1985, Madrid, MAPA.

FULGINITI, Lilyan E., y SHOGREN, Jason F. (1992): “Agricultural protection in developing countries", American Journal of Agricultural Economics, 74, pp. 795801.

GARDNER, Bruce D. (1986): Economic consequences of US agricultural policies, World Development Report Background Paper, Washington, The World Bank.

-(1987): "Causes of U.S. Farm Commodity Programs", The Journal of Political Economy, 95 (2), pp. 290-310.

-(1992): "Changing Economics Perspectives on the Farm Problem", Journal of Economic Literature, 30, pp. 62-101.

GÓMEZ ORBANEJA, Antonio, y CHECCHI, Alexandre (1980): La agricultura española: ¿rezagada o descarriada?: un estudio de la política de precios agrarios y sus efectos sobre la producción agraria española, Madrid, Moneda y Crédito. 
GUTIÉRREZ, Carmen (1983): “Una estimación del mercado negro de aceite de oliva en la posguerra española”, Agricultura y Sociedad, 29, pp. 153-173.

HATHAWAY, Dale E. (1963): Government and Agriculture, London, Collier-Macmillan.

HOFFMAN, Elizabeth, y LIBECAP, Gary D. (1991): “Institutional Choice and the Development of U.S. Agricultural Policies in the 1920s", The Journal of Economic History, 51 (2), pp. 397-411.

HONMA, Masayoshi, y HAYAMI, Yujiro (1986a): “The determinants of agricultural protection levels: an econometric analysis", en ANDERSON, Kym, y HAYAMI, Yujiro (eds.), The political economy of agricultural protection: East Asia in international perspective, Sydney, Allen and Unwin, pp. 39-49.

INGERSENT, Ken A., y RAYNER, Anthony (1999): Agricultural policy in Western Europe and the United States, Cheltenham, Edward Elgar.

INSTITUTO NACIONAL DE ESTADÍSTICA (varios años): Encuesta de Presupuestos Familiares, Madrid, INE.

JORDANA, Jacint, y RAMIÓ, Carles (2005): “Gobierno y Administración”, en CARRERAS, Albert, y TAFUNELL, Xavier (coords.), Estadísticas Históricas de España, siglos XIX y XX, Bilbao, Fundación BBVA, pp. 973-1026.

JOSLING, Timothy E. (1973): Agricultural Protection: Domestic Policy and International Trade, Roma, FAO.

-(1975): Agricultural Protection and Stabilisation Policies: A Framework of Measurement in the Context of Agricultural Adjustment, Roma, FAO.

KLATZMANN, Joseph (1972): Les politiques agricoles. Idées fausses et illusions, París, Presses Universitaires de France.

KRUEGER, Anne O.; SCHIFF, Maurice, y VALDÉS, Alberto (1991): Political economy of agricultural price policy, Baltimore, The Johns Hopkins University Press.

LEAL, José Luis; LEGUINA, Joaquín; NAREDO, José Manuel, y TARRAFETA, Luis (1986): La agricultura en el desarrollo capitalista español, 1940-1970, Madrid, Siglo XXI.

LIBECAP, Gary C. (1998): “The Great Depression and the Regulating State: Federal Government Regulation of Agriculture, 1884-1970", en BORDO, Michael D.; GOLDIN, Claudia, y WHITE, Eugene N. (eds.), The Defining Moment. The Great Depression and the American Economy in the Twentieth Century, Chicago y Londres, University of Chicago Press, pp. 181-224.

LINDERT, Peter (1991): "Historical Patterns of Agricultural Policy", en TIMMER, Peter (ed.), Agriculture and the State, Ithaca y Londres, Cornell University Press, pp. 29-83.

MAPA (1957): La política de sostenimiento de precios e ingresos en la agricultura y su relación con el precio del trigo y la producción triguera, Madrid, MAPA.

-(1971): Informe sobre politica de rentas y precios agrarios, Madrid, MAPA. 
MAPA-UAM (1977): Las subvenciones en la agricultura, Madrid, MAPA.

MARTÍN ACEÑA, Pablo, y PONS, M. Ángeles (2005): “Sistema monetario y financiero", en CARRERAS, Albert, y TAFUNELL, Xavier (coords.), Estadísticas Históricas de España, siglos XIX y XX, Bilbao, Fundación BBVA, pp. 657-706.

NAREDO, José Manuel (1986) "La agricultura española en el desarrollo económico", en GARRABOU, Ramón; BARCIELA, Carlos, y JIMÉNEZ-BLANCO, José Ignacio (eds.), Historia agraria de la España contemporánea, 3. El fin de la agricultura tradicional (1900-1960), Crítica, Madrid, pp. 455-498.

NARVÁEZ, Antonio (1980): Agricultura y desconcierto: la política de precios agrarios, Córdoba, Monte de Piedad y Caja de Ahorros de Córdoba.

OCDE (1974): Agricultural Policy in Spain, París, OCDE.

-(2002a): Agricultural Policies in OECD countries: Monitoring and Evaluation, París, OCDE.

-(2002b): "Methodology for the Measurement of Support and Use in Policy Evaluation", París, OCDE (http://wwww.OECD.org/agr/policy).

OLPER, Alessandro (2001): "Determinants of Agricultural Protection: The Role of Democracy and Institutional Setting", Journal of Agricultural Economics, 52, pp. 75-92.

OLSON, Marcus (1965): The Logic of Collective Action, Cambridge, Harvard University Press.

-(1985): "Space, Agriculture and Organization", American Journal of Agricultural Economics, 67, pp. 928-937.

PRADOS, Leandro (2003): El progreso económico de España (1850-2000), Bilbao, Fundación BBVA.

REIG, Ernest, y PICAZO, Andrés J. (2002): La agricultura española: crecimiento y competitividad, Alicante, Caja de Ahorros del Mediterráneo.

SCHULTZ, Theodore W. (1945): Agriculture in an Unstable Economy, New York, McGraw-Hill Book Co.

SERVOLIN, Claude (1989): L'agriculture moderne, París, Seuil.

SHEINGATE, Adam D. (2001): The Rise of Agricultural Welfare State: Institutions and Interest Group Power in the United States, France and Japan, Princeton, Princeton University Press.

SIMPSON, James (1995): Spanish Agriculture: The Long Siesta, 1765-1965, Cambridge, Cambridge University Press.

SOCIEDAD DE ESTUDIOS Y PUBLICACIONES (1969): El gasto público en la agricultura, 1958-1965, Madrid, Moneda y Crédito.

SPENCER, John E. (1985): “The European Economic Community: general equilibrium computations and the economic implications of membership", en PIGGOTT, John, y WHALLEY, John (eds.), New Developments in Applied General Equilibrium Analysis, Cambridge, Cambridge University Press. 
STEVENS, Robert D., y JABARA, Cathy L. (1988): Agricultural Development Principles: Economic Theory and Empirical Evidence, Baltimore y Londres, The Johns Hopkins University Press.

SUMNER, Daniel A., y TANGERMANN, Stefan (2002): “International Trade Policy and Negotiations", en GARDNER, Bruce L., y RAUSSER, Gordon C. (eds.), Handbook of Agricultural Economics, vol. 2, pp. 1999-2055.

SWINNEN, Johan F.M.; BANERJEE, Anurag N.; y GORTER, Harry de (2001): “Economic Development, Institutional Change and the Political Economy of Agricultural Protection. An Econometric Study of Belgium since the $19^{\text {th }}$ century", Agricultural Economics, 26, pp. 25-43.

TAMAMES, Ramón (1965): Estructura económica de España, Madrid, Servicio de Estudios y Publicaciones.

THIES, Cameron G., y PORCHE, Schuyler (2007): “The Political Economy of Agricultural Protection", The Journal of Politics, 69 (1), pp. 116-127.

TRACY, Michael (1989): Government and Agriculture in Western Europe 1880-1988, New York, New York University Press.

TYERS, Rodney, y ANDERSON, Kym (1992): Disarray in world food markets: a quantitative assessment, Cambridge-New York, Cambridge University Press.

WINTERS, Alan (1987): “The Economic Consequences of Agricultural Support: A Survey", OECD Economic Studies, 9. 